Jurnal Penelitian Perawat Profesional

Volume 2 Nomor 4, November 2020

e-ISSN 2715-6885; p-ISSN 2714-9757

http://jurnal.globalhealthsciencegroup.com/index.php/JPPP

\title{
PENGARUH REBUSAN DAUN SALAM TERHADAP PENURUNAN TEKANAN DARAH TINGGI PADA PENDERITA HIPERTENSI
}

\author{
Kristina L. Silalahi, Novelia Nainggolan, Sugianto Simanjuntak*, Ferry Anza Ginting \\ Fakultas Keperawatan dan Kebidanan, Universitas Prima Indonesia, Gg. Madrasah Sei Agul Kec. Medan \\ Barat, Kota Medan Sumatera Utara, Indonesia 20117 \\ *simanjuntaksugianto700@gmail.com (+6283843298899)
}

\begin{abstract}
ABSTRAK
Hipertensi merupakan salah satu penyakit yang paling mematikan atau sering disebut dengan sillent killer yg perlu mendapatkan perhatian khusus, pemberian rebusan daun salam merupakan salah satu pengobatan alternatif yang tidak mempunyai efek samping. Tujuan bertujuan untuk mengetahui pengaruh pemberian rebusan daun salam terhadap penurunan tekanan darah tinggi. Jenis penelitian ini adalah kuantitatif dengan desain penelitian Pre experimental dengan pendekatan one group pre-post test design yaitu mengungkapkan sebab akibat dengan cara melibatkan satu kelompok subjek. Penelitian ini melakukan dua kali pengukuran tekanan darah yaitu pengukuran tekanan darah dilakukan sebelum dan sesudah diberikan rebusan daun salam. Penelitian dilakukan di Panti Jompo Yayasan Guna Budi Bakti Medan pada bulan Agustus 2020. Sample dalam penelitian adalah lansia yang menderita hipertensi berdasarkan data dari rekam medik. Hasil penelitian yang telah dilakukan adalah adanya pengaruh antara pemberian rebusan daun salam terhadap tekanan darah pada lansia dengan nilai $\mathrm{p}$ sebesar 0,000 . Kesimpulan penelitian adalah ada pengaruh pemberian rebusan daun salam terhadap tekanan darah.
\end{abstract}

Kata kunci: hipertensi; lansia; tekanan darah

\section{THE EFFECT OF BRUSHED SALAM LEAF ON THE REDUCTION OF HIGH BLOOD PRESSURE IN HYPERTENSION PATIENTS}

\begin{abstract}
Hypertension is one of the most deadly diseases or often called silent killer what needs to get special attention, the stew laurel foliage is one alternative treatment with no side effects. The purpose of this research is to know the influence of the stew laurel foliage on reductions in high blood pressure. This is the kind of research with a quantitative research pre-experimental approaching one group pre-post test design the express and effect in a manner involving a group of the subject. This research does twice the measurement of blood pressure and blood pressure measurements conducted before and after the stew laurel foliage. The research was done in those elderly foundations to Budi medan in august by 2020. The sample is seniors who suffer from hypertension based on data from the medical record. The research has been conducted is the influence of the stew laurel foliage on the blood on the elderly 0,000 of p. The study areas are the stew leaf as regards any impact on blood pressure. It is hoped that the elderly established alternative treatment ( use stew leaf as regards hyperlens) to prevent a recurrence.
\end{abstract}

Keywords: blood pressure; Hypertensio; the elderly 


\section{PENDAHULUAN}

Menurut Susi dan Widiani (2018), Penyakit jantung dan pembuluh darah, termasuk hipertensi merupakan penyakit yang mematikan di negara berkembang maupun negara maju pada lebih dari delapan dekade terakhir. Hipertensi adalah gangguan yang terjadi pada sistem peredaran darah dan menyebabkan kenaikan tekanan darah diatas nilai normal, yaitu melebihi 140/90 mmHg, berdasarkan etiologi dibedakan menjadi 2 yaitu hipertensi primer dan skunder. Hipertensi disebut juga "silent killer" (pembunuh diamdiam), hal ini dikarenakan bahwa penderita hipertensi bertahun-tahun seringkali tanpa merasakan sesuatu gangguan ataupun gejala tertentu. Namun, tanpa disadari oleh individu yang menderita hipertensi, individu tersebut mengalami komplikasi pada organ-organ vital seperti jantung, otak ataupun ginjal. Gejala-gejala hipertensi seperti gangguan penglihatan, pusing dan sakit kepala, sering kali terjadi pada saat hipertensi sudah lanjut disaat tekanan darah sudah mencapai angka tertentu.

Data Word Health Organization (2015), menunjukkan bahwa persentase penderita hipertensi yang berusia 18 tahun keatas dengan peningkatan tekanan darah sistolik $\geq 140 \mathrm{mmHg}$ atau tekanan darah diastolik $\geq 90 \mathrm{mmHg}$ yaitu wanita 20,5\% dan laki-laki 24,0\%. Menurut WHO dan The International Society Of Hypertension (ISH), menyatakan bahwa terdapat 600 juta indivdu yang menderita hipertensi di seluruh dunia, dimana 3 juta diantaranya meninggal pada tiap tahunnya. Prevalensi hipertensi di Indonesia mencapai $31,7 \%$ dari populasi usia 18 tahun keatas, dimana $60 \%$ penderita hipertensi tersebut mengalami komplikasi stroke, sedangkan sisanya mengalami penyakit jantung, gagal ginjal, dan kebutaan. Hipertensi sebagai penyebab kematian ke 3 setelah stroke dan tuberkulosis, jumlahnya mencapai $6,8 \%$ dari proporsi penyebab kematian pada semua umur di Indonesia. Hipertensi harus mendapatkan pengobatan segera agar tidak menimbulkan stres, penelitian Sudawan dan Livana (2017) mendapatkan hasil bahwa lansia yang mengalami hipertensi berada pada tingkat stres sedang. Adapun faktorfaktor hipertensi meliputi faktor genetik, lingkungan, perilaku, dan pelayanan kesehatan (Kartika \& Livana, 2016).

Penderita tekanan darah tinggi akan mendapatkan obat penurunan tekanan darah bila menemui dokter, obatan tersebut diantarany golongan diuretik, penghambat adrenergik, ACE- inhibitor dan lain nya2. Pengobatan modern atau yang biasa disebut obat farmakologi biasanya dapat menimbulkan komplikasi yang tidak baik bagi tubuh apabila digunakan dalam waktu jangka panjang, sehingga di perlukan cara lain untuk mengatasi hipertensi dengan cara memberikan pengobatan herbal. Ada beberapa tanaman yang bisa di gunakan sebagai obat herbal seperti seledri, bawang putih mentimun, daun salam dan lainnya. Salam (Syzgiyum polyanthum) adalah nama pohon penghasil daun rempah yang banyak digunakan dalam masakan indonesia. Obat tradisional ini secara empiris berkhasiat dalam terapi hipertensi. Daun salam tumbuh menyebar di indonesia daun salam memiliki banyak mamfaat untuk kesehatan misalnya untuk pengobatan diabetes melitus, gastritis, diare, dan hipertensi (Aire, dkk, 2014).

Menurut savitri (2016), menyebutkan bahwa kandungan mineral yang terdapat 
pada daun salam mampu melancarkan peredaran darah dan mengurangi tekanan darah tinggi. Selain itu daun salam juga mengandung minyak esensial eugenol dan metal kavikol, serta etanol yang berperan aktif sebagai anti jamur dan bakteri. Kandungan kimiawi dari daun salam terdiri dari berbagai senyawa kimia seperti saponin, triterpen, flavonoid, tannin, alkaloid minyak atsiri (Seskuiterpen, lakto, dan fenol).

Berdasarkan survei awal yang di lakukan oleh peneliti di Yayasan Panti jompo Guna Budi Bakti Medan pada bulan januari 2020, di dapatkan data jumlah lansia yang tinggal di panti jompo tersebut berjumlah 73 orang, yg dimana laki-laki berjumlah 30 orang dan wanita berjumlah 43 orang. Diketahui dari hasil pemeriksaan kesehatan bahwa terdapat 38 lansia yang tinggal di panti jompo tersebut mengalami hipertensi baik ringan maupun berat. Dari wawancara yang peneliti bahwa rata2 penderita hipertensi menggunakan obat farmakologi untuk mengurangi tekanan darah dan ada juga yang mengurangi asupan garam dan menghindari makanan yang berlemak. Pengobatan atau tindakan seperti pemberian rebusan air daun salam belum dilakukan di panti jompo tersebut dan lansia disana belum mengetahui khasiat dari daun salam dalam menurunkan tekanan darah, mereka hanya mengetahui bahwa daun salam untuk campuran bumbu masakan saja. Tujuan penelitian untuk mengetahui pengaruh rebusan daun salam terhadap penurunan tekanan darah tinggi pada penderita hipertensi di yayasan panti jompo guna budi bakti pada tahun 2020 .

\section{METODE}

Desain Penelitian ini menggunakan metode pre experimental dengan pendekatan one group pre-post test design. Penelitian ini setelah dilakukan pada bulan februari 2020 pada 25 lansia hipertensi dan menetap di panti jompo yayasan guna budi bakti, responden diberikan minuman air rebusan daun salam sebanyak 1 gelas dua kali sehari selama satu minggu, lalu tekanan darah diukur sebelum dan sesudah tindakan selanjutnya dilakukan intervensi untuk mengetahui apakah ada perubahan penurunan hipertensi pada responden. tehnik pengambilan sampel menggunakan sampling jenuh dimana sampel penelitian ini adalah 25 orang yang menderita hipertensi. Data hasil penelitian dianalisis menggunakan distribusi frekuensi dan uji Wilcoxon Signed Rank Test.

\section{HASIL}

Hasil penelitian yang dilakukan pada bulan Agustus Pengaruh Rebusan Daun Salam Terhadap Penurunan Tekanan Darah Tinggi Pada Penderita Hipertensi Di Panti Jompo Yayasan Guna Budi Bakti Medan Tahun 2020 maka diperoleh hasil pada tabel 1.

Tabel 1, hasil dari data karakteristik jenis kelamin responden diatas jenis kelamin laki-laki dengan jumlah 5 responden $(25 \%)$ dan perempuan 15 responden (75\%). Sedangkan umur diperoleh dengan rentang 62-69 tahun berjumlah 5 responden (25\%) sedangkan 70-79 tahun berjumlah 9 responden (45\%) dan 80-89 tahun berjumlah 6(30\%). 
Tabel 1

Karakteristik Responden Berdasarkan Jenis Kelamin dan Umur $(\mathrm{n}=20)$

\begin{tabular}{lcc}
\hline Karakteristik & $\mathrm{f}$ & $\%$ \\
\hline Jenis Kelamin & & 25 \\
\hline Laki-laki & 5 & 75 \\
\hline Perempuan & 15 & \\
\hline Umur & & 25 \\
\hline $61-69$ & 5 & 45 \\
\hline $70-79$ & 9 & 30 \\
\hline $80-89$ & 6 & \\
\hline
\end{tabular}

Tabel 2.

Tekanan Darah Sebelum dan Sesudah diberikan Rebusan Daun Salam pada Lansia Hipertensi $(n=20)$

\begin{tabular}{lllll}
\hline Responden & \multicolumn{4}{c}{ Tekanan Darah Sistolik Tekanan Darah Diastolik } \\
\hline & Pretest & Posttest & Pretest & Posttest \\
\hline Mean & 166.50 & 137.50 & 104.00 & 79.00 \\
\hline Median & 170.00 & 140.00 & 100.00 & 80.00 \\
\hline
\end{tabular}

Tabel 3.

Perbandingan Hasil Uji Wilcoxon Signed Rank Test Sebelum dan Sesudah dilakukan Pemberian Rebusan Daun Salam $(n=20)$

\begin{tabular}{lcccc}
\hline Tekanan Darah & \multicolumn{2}{c}{$\mathrm{X} \pm \mathrm{SD}$} & \multirow{2}{*}{$\mathrm{Z}$} & \multirow{2}{*}{ P Value } \\
\cline { 1 - 3 } & Pre test & Post test & & 0,000 \\
\hline Sistol & 8,127 & 11,642 & 3,972 & 0,000 \\
\hline Diastole & 12,312 & 9,679 & 3,961 & \\
\hline
\end{tabular}

Tabel 2, diketahui dari hasil penelitian sebelum dan sesudah dilakukan senam jantung diperoleh nilai rata-rata tekanan darah sistolik sebelum dilakukan senam jantung adalah (166.50 $\mathrm{mmHg}$ ) dan setelah diberikan rebusan daun salam didapat hasil rata-rata $(137.50 \mathrm{mmHg})$. Setelah itu nilai dari tekanan darah diastolik sebelum diberikan daun salam rata-rata adalah $(104.00 \mathrm{mmHg})$ dan sesudah dilakukan pemberian rebusan daun salam didapat nilai rata-rata $(79.00$ $\mathrm{mmHg}$ ).

\section{PEMBAHASAN}

Hasil penelitian mengenai pengaruh rebusan daun salam terhadap penurunan tekanan darah pada lansia penderita hipertensi di panti jompo Yayasan Guna Budi Bakti Medan tahun 2020 dengan
20 responden sebagai sample. Frekuensi responden dari jenis kelamin menyatakan bahwa lebih menunjukan banyaknya responden berjenis kelamin perempuan dengan jumlah responden 15 (75\%). Sedangkan usia responden penderita hipertensi di Panti Jompo Yayasan Guna Budi Bakti Medan didapatkan hasil lebih banyak dari usia 61-69 tahun sebanyak 5 lansia (25\%).

Tabel 2. sebelum dan sesudah dilakukan pemberian rebusan daun salam hasil pengukuran tekanan darah sistol dan diastole sebelum dilakukan pemberian rebusan daun salam ialah sistol 166.50 $\mathrm{mmHg}$ dan diastol $104.00 \mathrm{mmHg}$. Dan setelah dilakukan pemberian rebusan daun salam terdapat hasil sistol 137.50 $\mathrm{mmHg}$ dan diastol $79.00 \mathrm{mmHg}$. Hal 
ini menunjukkan terjadinya penurunan tekanan darah pada lansia setelah melakukan pemberian rebusan daun salam selama seminggu. Hal tersebut juga dikatakan oleh Syaifurrahman Hidayat dkk pada pengaruh senam lansia terhadap penurunan tekanan darah pada lansia dengan $p$-value 0,024 . Berdasarkan hasil uji normalitas dengan menggunakan metode Shapiro-wilk yang dimana data sistol pre-test memiliki nilai sig $0,004<0,05$ sedangkan diastole pre-test dengan nilai sig $0,006<0,05$ sehingga demikian data tersebut tidak berdistribusi normal. Maka dari itu analisa data yang digunakan dalam penelitian ini ialah uji Wilcoxon Signed Rank Test.

Hasil dari uji Wilocoxon Signed Rank Test pre test dan post test didapatkan hasil dari tekanan darah diastole yaitu nilai $\mathrm{Z}$ sebesar 3.961 dengan $p$-value sebesar 0,000. Dari nilai uji $p$-value lebih kecil dari $0,05(0,000<0,05)$. Sehingga dapat kita artikan bahwa Ho ditolak terdapat perbedaan antara tekanan diastole pre-test dan post-test. Berdasarkan data tersebut disimpulkan bahwa ada pengaruh pemberian rebusan daun salam terhadap penurunan tekanan darah pada lansia penderita hipertensi $p$ value $0,000<0,05$ sehingga Ho ditolak dan Ha diterima. Penelitian ini sejalan dengan penelitian Dafriani (2016); Huda (2018); Aisyiyah, Mursudarinah, dan Mulyaningsih (2018); Friska (2016); Asih (2018) bahwa air rebusan daun salam berpengaruh terhadap penurunan tekanan darah.

Berdasarkan penelitian yang dilakukan oleh Eva, dkk (2018) dengan judul pengaruh pemberian daun salam terhadap penurunan tekanan darah pada penderita hipertensi dilingkungan kelurahan sei agul pada kelompok yang telah dilakukan intervensi senam lansia didapat hasil nilai $p$-value $0,000<0,05$ sehingga Ha diterima Ho ditolak.

Menurut asumsi peneliti penderita hipertensi harus rutin mengkomsumsi rebusan daun salam dapat menurunkan tekanan darahnya, karena dapat membantu meningkatkan aliran darah dan pemasukan oksigen kedalam otototot jantung dan merilekskan pembuluh darah. Rebusan daun salam, termaksud obat non farmakologi yang tidak menyebabkan efek samping kepada responden.

\section{SIMPULAN}

Rata-rata tekanan darah sistolik dan diastolic sebelum diberikan rebusan daun salam ialah 166.50/104.00 mmHg. Sedangkan setelah diberikan rebusan daun salam didapat hasil rata-rata tekanan darah sistolik dan diastolik ialah 137.50/79.00 mmHg. Ada Pengaruh Rebusan Daun Salam Terhadap Penurunan Tekanan Darah Pada Lansia Penderita Hipertensi Di Panti Jompo Yayasan Guna Budi Bakti Medan Tahun 2020 ( $\mathrm{p}$ value = 0,000).

\section{DAFTAR PUSTAKA}

Aisyiyah, I., Mursudarinah, M., \& Mulyaningsih, M. (2018). Penerapan Rebusan Daun Salam terhadap Penurunan Tekanan Darah pada Penderita Hipertensi. http://eprints.aiskauniversity.ac.id/id/eprint/869

Arie, N. N. M., Muntamah, U., \& Trimawati. (2014). Pengaruh Pemberian Air Rebusan Seledri Pada Lansia Penderita Hipertensi Di Dusun Gogodalem Barat. Jurnal Keperawatan Komunitas, 2(1), 46-51.

Aris, A. (2019). Pengaruh Pemberian Rebusan Daun Salam (Syzygium Polyanthum) Terhadap 
Penurunan Tekanan Darah Tinggi Di Desa Plosowahyu Kecamatan Lamongan Kabupaten Lamongan. 199-208.

https://doi.org/10.32528/psn.v0i0. $\underline{1747}$

Asih, S. W. (2018). Pengaruh Rebusan Daun Salam Terhadap Penurunan Tekanan Darah Pada Lansia Penderita Hipertensi Di Wisma Seruni Upt Pslu Jember. The Indonesian Journal of Health Science, (September), 169. https://doi.org/10.32528/ijhs.v0i0. 1543

Dafriani, P. (2016). Pengaruh Rebusan Daun Salam (Syzigium Polyanthum Wight Walp) Terhadap Tekanan Darah Pasien Hipertensi di Sungai Bungkal, Kerinci 2016. Jurnal Kesehatan Medika

Saintika, 7(2).http://dx.doi.org/10.30633/78 $2220162017 \% 25 \mathrm{p} 1$

Friska, R. (2016). Pengaruh Pemberian Daun Salam Terhadap Perubahan Tekanan Darah Pada Penderita Hipertensi di Wilayah Kerja Puskesmas Belimbing Kota Padang Tahun 2016 (Doctoral dissertation, UNIVERSITAS ANDALAS).http://scholar.unand. ac.id/id/eprint/17449

Huda, M. M. (2018). Pengaruh Pemberian Air Rebusan Daun Salam Pada Keluarga Yang Mengalami Hipertensi Di Wilayah Puskesmas Rowosai Semarang (Doctoral dissertation, Universitas Muhammadiyah Semarang).http://repository.unimu s.ac.id/id/eprint/2887

Nurhayati, E. L. (2018). Pengaruh Pemberian Air Rebusan Daun Salam (Syzigium Polyanthum) terhadap Penurunan Tekanan Darah pada Penderita Hipertensi di Lingkungan I Kelurahan Sei Agul Tahun 2018. Jurnal Ilmiah PANNMED (Pharmacist, Analyst, Nurse, Nutrition, Midwivery, Environment, Dentist), 13(2), 98101.

Sari, R. K., \& Livana, P. H. (2016). Faktor-Faktor yang Mempengaruhi Hipertensi. https://doi.org/10.32583/pskm.6.1. $\underline{2016.1-10}$

Sudawam, S., \& Livana, P. H. (2017). Gambaran Tingkat Stres Lansia dengan Hipertensi. Jurnal Ilmiah Permas: Jurnal Ilmiah STIKES Kendal, 7(1), 32-36. https://doi.org/10.32583/pskm.7.1. $\underline{2017.32-36}$

Susi, S., Widiani, E., \& Ahmad, Z. S. (2018). Faktor-Faktor yang Berhubungan dengan Tekanan Darah pada Lansia Penderita Hipertensi di Desa Landungsari, Kecamatan Dau Kabupaten Malang. Nursing News: Jurnal Ilmiah Keperawatan, 3(3).

Wang, G., Sun, N., Gao, C., Zhu, X., Sun, Y., Li, C. L. C., ... Ganesh, I. (2013). No Title大学生の職業未決定の研 究. Applied Catalysis A: General, 58(2), 15-22. https://doi.org/10.1179/17432804 $\underline{12 Y .0000000001}$

Nurhayati, E. L., \& LUBIS, M. Y. (2020). Pengaruh Pemberian Air Rebusan Daun Salam (Syzigium Polyanthum) Terhadap Penurunan Tekanan Darah Pada Penderita Hipertensi di Lingkungan I Kelurahan Sei Agul Tahun 2018. 